\title{
RESEARCH ARTICLE \\ The seamless web of \\ next generation sequencing \\ and Covid-19
}

Karen Kastenhofer, Institute of Technology Assessment, Austrian Academy of Sciences, Apostelgasse 23, 1030 Vienna, AT (kkast@oeaw.ac.at) (D) 0000-0001-5843-6489

Abstract - "When is Covid Covid?" is the title of a discussion paper published by the Centre for Evidence-Based Medicine at Oxford University on 11 September 2020. Amid the multinational struggle for an appropriate social and political approach to the crisis triggered by Covid-19, a recognized panel of medical experts alerts us that Covid-19 is defined very differently in different contexts. One definition focuses on symptoms, another one on RNA sequences of the virus. In the present contribution, this debate is taken up to discuss the extent to which new sequencing practices and their "seamless webs" become socially effective as instances of interpretation and design. At the same time, the limitations of such webs become noticeable as ruptures, seams, and scars.

\section{Next Generation Sequencing und Covid-19 als nahtloses Netz}

Zusammenfassung • "Wann ist Covid Covid?" titelt ein Diskussionsbeitrag des Centre for Evidence-Based Medicine der Universität Oxford vom 11. September 2020. Inmitten des multinationalen Ringens um einen geeigneten gesellschaftlichen wie politischen Umgang mit der durch Covid-19 ausgelösten Krisensituation weist ein anerkanntes medizinisches Expert*innengremium darauf hin, dass Covid-19 in unterschiedlichen Kontexten sehr unterschiedlich definiert wird. Bei einer Definition geht es um klinische Symptome am Menschen, bei einer anderen um RNASequenzen des Virus. In dem Beitrag wird diese Frage aufgegriffen und diskutiert, inwiefern neue Sequenzierungspraktiken und deren "nahtlose Netze" als Deutungs- und Gestaltungsinstanzen gesellschaftlich wirkmächtig werden. Dabei zeigen sich auch die Grenzen solcher Netze in Form von Brüchen, Nähten und Narben.

Keywords · seamless web, next generation sequencing, Covid-19

This is an article distributed under the terms of the Creative Commons Attribution License CCBY 4.0 (https://creativecommons.org/licenses/by/4.0/) https://doi.org/10.14512/tatup.30.2.18

Received: Feb. 05, 2021; revised version accepted: May 05, 2021;

published online: Jul. 26, 2021 (non-blind peer review)

\section{Introduction}

The recent history of Covid-19 is closely linked to Next Generation Sequencing (NGS). Taking a closer look at this link between an emerging pandemic and NGS as a technique, practice, paradigm and network allows for addressing potential ramifications not of NGS 'per se', but of technoscience-in-context. The following article is dedicated to this ambition.

From its very beginning, a central role in identifying, observing, and processing the current pandemic was assigned to the molecular-genetic virological dimension of the disease, that is, the SARS-CoV-2 viral ribonucleic acid (RNA). The local spread of a previously unknown respiratory syndrome in the Chinese province of Wuhan was linked to the emergence of a novel virus in the Chinese population in autumn 2019 and confirmed as a new disease (coronavirus disease 2019 or Covid-19) at the end of December. The first complete sequences of the viral genome were submitted about eight weeks later, in early March 2020. Whole-genome sequencing of the virus was achieved via the use of Next Generation Sequencing methods (Zhou et al 2020; Wu et al 2020) and led to the characterization, categorization and naming of the virus. Based on this, hypotheses were formulated about the origin of the virus from specific animal populations. NGS has contributed and continues to contribute to describing and differentiating different populations of the novel virus and monitoring the virus' further genetic evolution. Knowledge of the complete genome informs the development of effective vaccines as well as the development of appropriate testing methods that can detect and quantify the respective viral load. Recently, even clinical testing methods based on whole-genome sequencing via NGS techniques have been approved. In contrast to the common real-time PCR tests, which only react to the presence of small but characteristic sections of the viral genome in a sample (sections that had previously been established by whole-genome sequencing), NGS-based tests sequence the entire viral genome present in the sample and allow for the detection of variants and mutations. 


\section{NGS in the seamless web of techno- science}

NGS is presented in expert literature and in mass media as a new tool, simply adding to the existing techno-scientific toolbox, opening up for new possibilities via faster and cheaper genome sequencing and bringing about some limitations (such as decreasing reliability with increasing sequence length). As early as 1986, however, the historian of technology Thomas Hughes pointed to an alternative view of technology that does not focus on new techniques in isolation, refraining from a categorical separation of objects, techniques and actors, or actor fields such as science, technology or society. Along with this concep- resents a seamless web, whether it comes with no loose ends at all, is another question addressed later in this text.

Remarkably, very useful, high-quality explanatory videos on NGS are being provided via internet platforms. These videos combine scientific-technical explanations from "What is DNA?" to "How does genome sequencing work?" (Chow 2019), infotainment and promotion of sequencing equipment. They explain that NGS encompasses several different sequencing approaches, that all share significant differences from traditional (i. e., Sanger) sequencing. They present relevant differences between the various NGS approaches and relating next generation sequencing machines and discuss appropriate fields of application. It can be assumed that these didactically sophisticated vid-

\section{The implementation of next generation sequencing requires the active construction and expansion of a seamless web of actors, practices, ontologies and objects.}

tion, technology and technological change are realized through "seamless webs", their heterogeneous professionals and organizations: "Heterogeneous professionals - such as engineers, scientists and managers - and heterogeneous organizations - such as manufacturing firms, utilities, and banks - become interacting entities in systems or networks. [...] Technology and science, pure and applied, internal and external, and technical and social, are some of the dichotomies foreign to the integrating inventors, engineers, and managers of the system- and network-building era." (Hughes 1986, p. 282, 286). Similar perspectives have been brought to bear by other science and technology researchers such as Michel Callon, Bruno Latour, John Law and Annemarie Mol. But these approaches, roughly summarized as actor-network theory, mostly lack the historical diagnosis that seamless webs -like networks - are a phenomenon linked to a certain era.

A closer look at the practices, instruments and actors involved in NGS promotes the diagnosis of a seamless web: NGS is carried out via specially developed sequencing equipment provided by a few market leaders in this field. The results of the genetic sequencing itself are of very limited informational value. Only in comparison with other genomic sequences and relating metadata deposited and archived in sequence databases do they become interpretable in different directions. Sequence databases, in turn, require consortia that define uniform annotation standards and access options; they must be maintained and checked for legal and ethical aspects. Since the costly creation and maintenance of sequence databases is currently the real brake on high-scale viral whole-genome sequencing, NGS methods are being adapted to best support existing databases (Gohl et al. 2020). Thus, an almost endless network of actors, practices, rules, ontologies and objects is constructed. Whether this endless network also rep- eos are also used in academic education. Some of them feature recognized professors from renowned universities. It is not always easy to see whether a private company and/or a public university is behind these videos; an interesting example of a public-private partnership at the level of scientific didactics as well as another part of the seamless web of which NGS is part!

Conversely, the implementation of NGS requires the active construction and expansion of a seamless web of actors, practices, ontologies and objects. This task is incumbent on "heterogeneous engineers": "The technologist [heterogeneous engineer] has to be seen as attempting to build a world where bits and pieces, social, natural, physical or economic, are interrelated", as Hughes (1986, p. 289) quotes his colleague Law' ${ }^{1}$ Simultaneously, the importance of categorical differences fades: the heterogeneous engineer is as much an inventor as a scientist or entrepreneur. NGS is thus not just another element in the techno-scientific repertoire; it requires the practice of heterogeneous engineering attributed to the figure of the heterogeneous engineer; it entails the consolidation of existing and/or the construction of new networks of actors, practices, rules, ontologies and objects. Any action or innovation that affects one element of the network will impact on the whole system and its components.

Such a connection has already been drawn in many examples in the history of science and technology, for example in Bruno Latour's account of the "Pasteurisation of France" (Latour 1988). The disciplining aspect of socio-technical innovation is a central theme in Foucault's work on health care or prisons (Foucault 1976). However, the world has continued to change since Latour's and Foucault's empirical case studies and so has the scientific realm. Shapin (2008) depicts this change for the

1 However, the quotation could not be found in the referenced text. 
life sciences, he devises the figure of the heterogeneous engineer under the label scientific entrepreneur. Digitally supported platforms connecting network nodes are themselves becoming lucrative business models. They are being critically discussed, for example, under the general catchword network capitalism (Srnicek 2016) or in relation to distinct contexts and issues such as "seamless webs of surveillance" established by the Internet of Things (Sadowski and Pasquale 2015).

\section{The seamless web of Covid-19}

With the detection of a new pandemic, its molecular-genetic characterization as SARS-CoV-2 and the (further) development of corresponding networks, the new disease has been successfully established as a molecular-genetic-virological-epidemiological event, a seamless picture of the current situation has emerged and is continuously being stabilized.

Not every subjective feeling of illness, not every clinically observed and medically characterized clinical symptom, is primarily investigated at the molecular genetic level, either because a causal relationship is not (yet) assumed or because it could not (yet) be determined. A robust causal connection between the genetic level and the phenomenological level of a clinical symptom is drawn in our understanding and treatment of hereditary diseases, mutation-based syndromes and genetic predispositions, but also for viral diseases. In the former cases, it is the genome of the diseased; in the latter case, the virus' genome plays
Access to the viral (or microbial) component, on the other hand, is socially rehearsed and established - one could also say seamlessly compatible with established networks of actors, practices, rules, ontologies and objects. New feasibilities, as opened up by NGS procedures, support such an approach from the techno-scientific side. They essentially allow for more genetic material to be sequenced in less time at a lower cost. ${ }^{2}$ Thus, science, politics, and the public increasingly focus on the virological properties, molecular genetic characteristics, and epidemiological events in the current crisis.

The witnessed short-term change of focus from clinical symptoms to molecular genetics, virology and epidemiology attends to an obvious rationale: it is paramount to bring a rapidly developing epidemiological event resulting in quickly increasing death rates worldwide under control as effectively as possible. New possibilities of molecular genetic characterization are being exploited and further developed to better understand this side of the pandemic. This gives rise to hopes for a better understanding of the origin of the pandemic and the further development and diversification of the virus, for the development of adequate test kits, for better prevention through appropriate behavioral rules and - last but not least - for effective vaccines. Besides the demand for utmost accuracy of sequencing, there is also the need for maximum throughput to enable the characterization of as many virus samples as quickly and as detailed as possible.

When all societal efforts focus on one perspective - in this case, linking molecular genetics, virology and epidemiology it is not long before visible successes are being achieved. Enor-

\section{The connection between clinical symptoms and genetic characteristics is more complex than simple cause-and-effect models would suggest.}

the central role. In both cases, the connection between clinical symptoms and genetic characteristics is more complex than simple cause-and-effect models would suggest: the causal relationship between genetic risk factors and the risk of disease is not always clear. The categorization of a disease as a viral disease is sometimes ambiguous: the presence of the virus, its quantitative load and other factors on the part of the patient, such as lifestyle-associated or genetic factors, play a role.

Nevertheless, viral diseases, their treatment and containment are often successfully based on the viral factor alone. This may be partly because such treatments show substantial efficacy, partly because other factors are beyond immediate reach for various reasons. Lifestyle changes, for example, will only have an impact in the medium to long term. Moreover, the choice of lifestyle is (essentially) still considered a personal, free decision. Access to the human genome is neither legally permissible nor is it (currently) technically feasible in a precise, controlled manner. mous knowledge about the new virus has been gathered. The virus has been named and categorized. The genome has been completely sequenced several times. Internationally accessible archives with extensive data material on locally emerging mutations have been created and continuously expanded. The virus' origin from animal populations and its transmission through intermediate hosts to humans is being researched. In an incredibly short time, highly effective vaccines have been developed, approved and put into use. Last but not least, we have all learned to move and behave risk-consciously in public spaces, from keeping distances the size of baby elephants (an expression that became famous in the Austrian primary education context) to hand hygiene and face masks. Public space has been rapidly trans-

2 The extent to which this leads to losses in the accuracy or reliability of sequencing in comparison to classical sequencing technology cannot be discussed here; however, such a trade-off is to be assumed to a certain extent. 
formed into a laboratory to a level that even Bruno Latour could not have anticipated more accurately. An entire generation will no longer associate face masks with safety labs or operating theatres, but with the weekly family trip to the grocery store and an on-off attendance at school.

So much for the enormous success story of the focus on SARS-Cov-2 and its genetic sequence in the current pandemic. symptoms. Sequence-based definitions differ in test method, detecting either viral sequences or antibodies. These comprise essentially real-time PCR methods, based on the amplification of genetic material by polymerase chain reactions and subsequent detection of this material in the sample. NGS only provides the reference frame by providing data on the complete viral genome.

\section{How to infuse a broader horizon and a tolerance of diversity in these times of crisis?}

The sudden and exclusive molecular-genetic focus, however, obfuscates other relevant factors (such as lifestyle or income level), rendered previously established practices (such as medical diagnostics) incompatible and banished alternative horizons of perception and concern - such as those of curative treatments of symptoms or of addressing long-term societal and ecological impacts. In the short term, these may be unintended side effects that we as a society consciously or unconsciously accept. But what if they stand in the way of dealing productively with the pandemic in the medium and long term? In the following, the unintended side effects of our highly successful short-term molecular-genetic-virological view will be taken into account to discuss why we may have to broaden our horizon again to ensure long-term success.

\section{"When is Covid Covid?": on seams and fractures}

Evidence-based medicine propagates placing clinical action on the best available factual basis. Its rather pragmatic take on addressing everyday practical challenges of clinical decision making rarely results in extensive terminological treatises. And yet, the Centre for Evidence-Based Medicine at Oxford University posed an almost philosophical question on 11 September 2020: "When is Covid Covid?" (Spencer et al. 2020). The practical relevance of this question is quickly explained: Covid-19, according to the authors' research, is defined very differently in different national contexts. The contribution contrasts the diagnostic guidelines of the WHO, the European Centre for Disease Prevention and Control (ECDC) of the European Union, the Centers for Disease Control of the USA, the British and the Italian governments. The most significant consensus concerns the detection of confirmed cases. It is almost always based on positive laboratory tests. But even in this case, the technical details often remain unclear, and further incongruences abound.

Moreover, some definitions focus on confirmed cases, others on probable cases or suspected cases. One time, a definition is based solely on the prevalence of specific viral RNA sequences in a sample; another time, it encompasses clinical
And finally, test results are interpreted in different ways, e.g., regarding the minimum threshold of viral load in the sample that would result in a positive test. Treatment and prevention practices based on such diagnostic methods can either focus on case-based clinical decision-making, or on adapting individual behavior, or on population-wide management strategy. Practices thus focus either on the clinical symptoms and their improvement, or on assessing and minimizing the probability that the virus will continue to be transmitted in epidemiologically relevant quantities, or on predicting and responding correctly to the pandemic development as a whole. Spencer and colleagues (2020) call for the harmonization of lower limits of the viral load and for the complimentary recording of clinical symptoms (the recording of lung CTs and serological findings in hospitals) to allow for transnational comparability and a more comprehensive definitory approach.

The web of actors, practices, rules, ontologies and objects thus obviously features seams and fractures along the national borders of regulatory regimes that need to be attended to by a kind of sewing work. Transnational evidence-based medicine is taking on this critical task, as are other relevant actors. Further seams or fractures result from different orientations of action within scientific research, clinical practice and pandemic management. Gathering new and robust insights, treating individual patients and getting a pandemic under control do not always go hand in hand without frictions.

\section{Webs, seams and loose ends}

When we speak of seamless webs, seams and fractures in the context of NGS and Covid-19, we are essentially talking about the characterization of a context of action in which NGS can be seen as an element or - in the language of actor-network theory as an actant. Along with such a conception, NGS is not a passive $\operatorname{cog}$ in a superordinate wheel but an active part that co-defines an entire network of actors, practices, ontologies, rules and objects. Conversely, we can also assume that NGS, and techno-science more generally, are being shaped by their role in the pandemic. Thus, the rules that govern techno-science can change in times of crisis. Well-known examples include pre-review publi- 
cations and fast-track approvals, which impinge on established routines of quality assurance. At the same time, there are calls for additional techniques of quality assurance to re-stabilize the network. Established funding and ownership models are also being re-discussed (Ravi Srinivas 2020).

The individual elements of this web not only communicate with each other, they condition and constitute each other. Thereby, coordination does not predominantly occur on a meta-level (e.g., through formulating explicit rules and implementing them via regulatory agencies), but rather in a mechanical manner ${ }^{3}$. The fewer seams, fractures and loose ends a web holds, the more ubiquitous and far-reaching such almost mechanical coordination effects can become. In the present context of Covid-19, fractures, seams and loose ends become apparent that resist and sometimes sabotage such coordination. Given the rather frightening idea of ubiquitous coordination by a seamless techno-scientific web (reminiscent of science fiction prose that paints dystopian pictures about machines or the mechanical principle taking over our lifeworld), such ruptures indeed open up for welcome interference.

However, another extreme is also worrying: what if ruptures, seams and loose ends become so dominant that socio-political coordination is no longer possible at all? Fractures at the level of national regulatory regimes and divergent fields of practice have already been mentioned above. They seem workable when acknowledged and addressed. If we recognize that good clinical practice is based on different objectives, success criteria and quality standards than the epistemic practice of virological and epidemiological research or the governmental practice of pandemic management, much can be gained. native; the (semiotic) web appears seamless for the time being. The advantage of such alleged seamlessness is a maximum of coordination and thus the ability to react quickly and effectively. But with time elapsing, we have to address the question of how long our societies can tolerate such a mechanical state, ignoring existing ruptures, postponing necessary sewing work and drying out alternative networks.

Moreover, a first phase of maximum coordination seems to have been followed by a second phase, marked by increasing resistance (passive as motivational Corona fatigue and active as public protest), infodemias and urban legends. All this points towards the fractures and loose ends of the dominating network to which NGS belongs. This does not mean that it is an ineffective, dysfunctional or even morally bad network. But it shows us that we as a society still have a lot more to look at and work on; or in other words, we cannot and must not be wholly absorbed in this - or any other - single web.

\section{Discussion: the diagnosis of a (not so) seamless web}

An end to the current pandemic is currently not in sight: vaccination alone may not terminate the current crises; further pandemics of similar magnitude cannot be ruled out. The network to which NGS essentially belongs (including its heterogeneous engineers, practices, rules, ontologies and objects) seems to have been the only network that could provide practical answers to the life-threatening situation in the short term. Therefore, there can be no question of abandoning it; on the contrary, demand -

\section{Lasting pandemic prevention needs complementary approaches, especially those dedicated to preserving near-natural ecosystems.}

But what about our collective, public understanding of the pandemic and its mitigation in contemporary societies at large? How to navigate between a worrying picture of total coordination by a seamless web of aligned actors and similarly dangerous fundamental fragmentation based on divergent interests, ontologies or values? How to infuse a broader horizon and a tolerance of diversity in these times of crisis? It is striking that this first year of the pandemic has been characterized by a relative impoverishment of narratives, perspectives and approaches. In public discourse, too, a single, narrative seems to prevail without alter-

3 An interesting aspect in this respect is that the pandemic's central figure the virus - is depicted in contemporary culture as "a kind of missing link", "a necessary interface between viralism and mechanism" (Ristow 2021, translation by the author). further promoted by an increasing technology push - will probably continue to rise. Questions nevertheless accrue: in the short and medium-term, concerning the maintenance work that is in any case necessary to ensure the coordination within the network (for example, further developing and maintaining broadly accessible genome databases), concerning the sewing work to promote a robust alignment of relevant actors and actor fields.

In the long run, the question arises whether the existing biomedical web (for a critical analysis of this term and its use, see Cambrosio and Keating 2003; Bruchhausen 2010) of which NGS is a part can address all possibilities for pandemic prevention and management. For example, whole-genome sequencing has pointed to the origin of the virus from animal populations. Ecologists have already spoken out in this regard: lasting pandemic prevention needs complementary approaches, especially 
those dedicated to preserving near-natural ecosystems and, thus, bio-ecological resilience (Daszak et al. 2020). However, to integrate corresponding actors, practices, rules, ontologies and objects into the existing biomedical web, the currently prevailing heterogeneous engineers do not seem to be heterogeneous enough by far. This concerns not only the elements of the seamless web, but also the attitude of its engineers, which in the best case should also enable curative work and acknowledge diversity and inevitable loose ends.

The concept of the seamless web as put forward by sociologist-historians of science and technology allows for discussing and comparing alternative kinds of networks, with or without seams, with strong or weak ties, endless or finite. It allows for addressing seams (Žižek 2001), fractures, scars (reminiscent of Mary Shelley's figure of Frankenstein) and loose ends from a broader, socio-cultural perspective. NGS and Covid-19 mitigation are certainly not the only context in which such discussions might be favorable (see also Schubert 2019 for the application of the concept to the analysis of Covid-19 vaccination), but they can serve as a worth-while and timely exemplary case.

\section{References}

Bruchhausen, Walter (2010): ,Biomedizin' in sozial- und kulturwissenschaftlichen Beiträgen. Eine Begriffskarriere zwischen Analyse und Polemik. In: NTM Zeitschrift für Geschichte der Wissenschaften, Technik und Medizin 18 (4), pp. 497-522. https://doi.org/10.1007/s00048-010-0039-9

Cambrosio, Alberto; Keating, Peter (2003): Qu'est-ce que la biomédecine? Repères socio-historiques. In: Medicine/Sciences 19 (12), pp. 1280-1287. https://doi.org/10.1051/medsci/200319121280

Chow, Eric (2019): Next generation sequencing 1. Overview. Available online at https://www.youtube.com/watch?v=ml0Fo9kaWqo, last accessed on 10. 05. 2021.

Daszak, Peter; Olival, Kevin; Li, Hongying (2020): A strategy to prevent future epidemics similar to the 2019-nCoV outbreak. In: Biosafety and Health 2 (1), pp. 6-8. https://doi.org/10.1016/j.bsheal.2020.01.003

Foucault, Michel (1976): Überwachen und Strafen. Die Geburt des Gefängnisses. Frankfurt a. M.: Suhrkamp.

Gohl, Daryl et al. (2020): A rapid, cost-effective tailed amplicon method for sequencing SARS-CoV-2. In: Bmc Genomics 21, p. 863. https://doi.org/10.1186/ s12864-020-07283-6

Hughes, Thomas (1986): The Seamless Web. technology, science, etcetera, etcetera. In: Social Studies of Science 16 (2), pp. 281-292. https:// doi.org/10.1177/0306312786016002004

Latour, Bruno (1988): The pasteurisation of France. Cambridge, MA: Harvard University Press.

Ravi Srinivas, Krishna (2020): Intellectual property rights and innovation in the times of Corona epidemic. In RIS Policy Briefs 89. Available online at https://infojustice.org/wp-content/uploads/2020/04/RaviSrinivas.pdf, last accessed on 05. 02.2021.

Ristow, Susanne (2021): Kulturvirologie. Das Prinzip Virus von Moderne bis Digitalära. Berlin: De Gruyter. https://doi.org/10.1515/9783110728583

Sadowski, Jathan; Pasquale, Frank (2015): The spectrum of control. A social theory of the smart city. In: First Monday 20 (7). https://doi.org/10.5210/ fm.v20i7.5903
Schubert, Cornelius (2019): Impfen. In: Pop. Kultur und Kritik 8 (2), pp. 54-59. https://doi.org/10.14361/pop-2019-080208

Shapin, Steven (2008): The scientific life. A moral history of a late modern vocation. Chicago, IL: University of Chicago Press. https://doi.org/10.7208/ chicago/9780226750170.001.0001

Spencer, Elizabeth; Jefferson, Tom; Brassey, Jon; Heneghan, Carl (2020): When is Covid, Covid? In: The Centre for Evidence-Based Medicine. Available online at https://www.cebm.net/covid-19/when-is-covid-covid/, last accessed 10.10.2020.

Srnicek, Nick (2016): Platform capitalism. Cambridge, UK: Polity Press.

Wu, Fan et al. (2020): A new coronavirus associated with human respiratory disease in China. In: Nature 579 (7798), pp. 265-269. https://doi.org/10.1038/ s41586-020-2008-3

Zhou, Peng et al. (2020): A pneumonia outbreak associated with a new coronavirus of probable bat origin. In: Nature 579 (7798), pp. 270-273. https://doi. org/10.1038/s41586-020-2012-7

Žižek, Slavoj (2001): Die Furcht vor echten Tränen. Krzysztof Kieślowski und die „Nahtstelle“. Berlin: Volk und Welt.

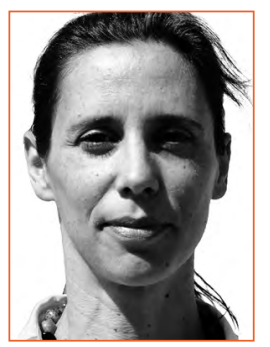

\section{DR. KAREN KASTENHOFER}

is a science and technology studies scholar and TA practitioner with an academic background in biology. Her research focuses on technoepistemic cultures, technoscientific controversies and the governance of biotechnoscience. She coordinated the research project Techno-Epistemic Cultures in $21^{\text {st }}$ Century Life Sciences with support of the Austrian Science Fund (FWF V-383, 2014-2019). 